\title{
Moves and Linguistic Features in Master's Theses Acknowledgments
}

\author{
Frederick Grengia and Ed D
}

\begin{abstract}
The study examined the generic moves of theses acknowledgements written by thirty (30) Filipino graduate students, with the aim of specifying the rhetorical preferences of these Filipino student writers in terms of moves and steps as well as the use of sentence patterns, modifiers and hedges employed in thanking acts and the choice of sentence subjects. The basic theoretical framework is from the pioneering studies of Hyland (2004) and Hyland \& Tse (2004).

For corpus analysis and move analysis, the researchers employed the simple frequency count, averages, and percentages to determine the total number of words in the corpus, length of words, occurrences of moves and steps in generic structure.

The generic structure of the theses acknowledgements of the selected graduate students consisted of three moves: the reflective move, thanking move, and signing-off move. The signing off move was evident and considered as an additional move. Only the second move, the thanking move, was obligatory. Thanking God was added as part of the thanking move. Of all the moves, the thanking move got the highest frequency. Thanking for academic assistance and thanking for moral support both got $96.6 \%$.

Of the 30 acknowledgements, 46 acts of gratitude were found being used to realize steps in the thanking move. Graduate students used more performative verbs than nouns.

Thirty-nine (39) \% of their thanking verbs were prefaced by a modal would like to while 10 or about $30 \%$ were mental state verbs like wish to and want to. Modifiers in thanking acts included adjectives (e.g. heartfelt, sincere, special, deep/est, most of all, and above all) and adverbs (e.g. humbly, sincerely, and heartily) which were often attached to thanking acts in the chosen graduate theses.
\end{abstract}

Keywords - move analysis, linguistic analysis, corpus analysis.

\section{INTRODUCTION}

In recent decades, there have been increasing scholastic interests in analyzing texts in academic and research setting. Different academic genres ranging from research theses (Thompson, 2001; Bunton, 2002) to research articles (Swales, 1990; Posteguillo, 1999), from textbooks (Hyland, 2000) to book reviews (Nicolaisen, 2002), and from conference papers (Rowley-Jolivet, 2002) to grant proposals (Halleck \& Connor, 2006) have been the subjects of detailed analysis. Various approaches have been employed to unveil general characteristics of academic discourse as well as features of particular genres. These include, among others, the corpus-based "multi-dimensional analysis" (Biber, 1995) and the anthropological approach (Bazerman, 1988), the Systemic

Frederick Grengia and Ed D, J.H. Cerilles State College, Mati, Zamboanga del Sur, Philippines
Functional Linguistics approach (Nwogu, 1990) and the move-based model (Swales, 1990; Bhatia, 1993).

As research in the field of genre analysis progressed, academic acknowledgements, part of the academic landscape in monographs, theses and dissertations and, even, journal articles, since 1990s, began to interest genre researchers. While Hyland and his colleague's pioneering work has unveiled the common generic structure of the academic acknowledgments as a genre, the significance of Al-Ali (2006) lies in its findings of cross-cultural similarities and differences in such texts.

Therefore, it would be interesting to examine academic acknowledgments written by Filipino writers to reveal the generic structure of these texts and the lexico-grammatical patterns they use to realize the moves and steps of their academic genre- their theses acknowledgements.

Previous studies on acknowledgements, particularly those accompanying theses or dissertations have shown that acknowledgements in a particular academic community have a certain structure and linguistic patterns which are partly influenced by the culture in which the acknowledgers are involved. Writing acknowledgements in L1 and in one particular area of study can reveal clearly that the writers belong to one academic community and society, as clearly shown in Al-Ali (2010), while writing acknowledgements in L2 has shown that the acknowledgers, even though they may have to conform to the conventions held in common in the L2 academic community, may be influenced by their L1 culture, especially when they write L2 acknowledgements in the L1 context, as clearly shown in Roungtheera (2010).

\section{RESEARCH QUESTIONS}

The following are the specific questions the study sought to answer:

1. How do SCC graduate students formulate their theses acknowledgments in terms of generic moves?

2. What lexico-grammatical features are employed in their writings?

\section{THEORETICAL FRAMEWORK/MODEL}

This study employed the generic structure used by Hyland (2004) and Hyland and Tse (2004) on notion of move analysis with modifications and additions of certain moves.

\section{A. Research Design}

This study utilized the quantitative-qualitative method of analyzing the data. For corpus analysis and move analysis, the 
researchers employed the simple frequency count, averages, and percentages to determine the total number of words in the corpus, length of words, occurrences of moves and steps in generic structure. For in-depth analysis of descriptive data, a qualitative method was used.

\section{B. Corpus and Procedure}

As shown in Table 1 below, the data comprised of 30 graduate thesis acknowledgments with a total length of 7,249 words or an average text length of 243.13 words. The longest

TABLE I. AVERAGE LENGTH OF ACKNOWLEDGMENTS IN THESES OF SAINT COLUMBAN COLLEGE

\begin{tabular}{lllll}
\hline \hline Sub-Corpora & No. of Texts & Words & Average \\
\hline \multirow{2}{*}{ MAED } & & & & \\
& Educational Management & 5 & 1,117 & 223.4 \\
& English & 5 & 1,022 & 204.4 \\
& Mathematics & 5 & 1,159 & 231.8 \\
& Science & 5 & 1,027 & 205.4 \\
MA & & & & \\
MLIS & Guidance and Counselling & 5 & 1,732 & 346.4 \\
\hline \multirow{2}{*}{ Total } & & 5 & 1,237 & 247.4 \\
\hline
\end{tabular}

Following Swales (2004) and Hyland (2004) regarding their notion of move analysis, the data in this research were analyzed to find out their generic structure: moves and steps. As acknowledgements are a genre that is not involved in any special science that requires another expert to create an inter-coding, the data in this research were analyzed by the researcher himself. Then the analysis of linguistic features was carried out to find the language patterns of gratitude expression and also the data were analyzed for the sociocultural aspects that they might convey. For the sake of research ethics, any real first or last names of people mentioned in the data were coded respectively. sub-corpus contains an average of 346.4 words (MA-Guidance and Counselling), while the shortest one contains an average of 204.4 words (MAED-English). The corpora were taken from the selected theses of graduate students enrolled in different programs of Saint Columban College namely: Master of Arts in Guidance and Counselling, Master in Library and Information Science, Master of Arts in Education (MAED) majors in: Educational Management, English, Mathematics, and Science.

\section{Research Instrument}

The researcher used the Antconc software to determine the total number of words and average text length per sub-corpus.

\section{RESULTS AND DISCUSSION}

\section{A. Generic Moves}

Table 2 shows that the generic moves of English acknowledgements of the selected graduate students consists of three moves: the reflective move, thanking move, and signing-off move.

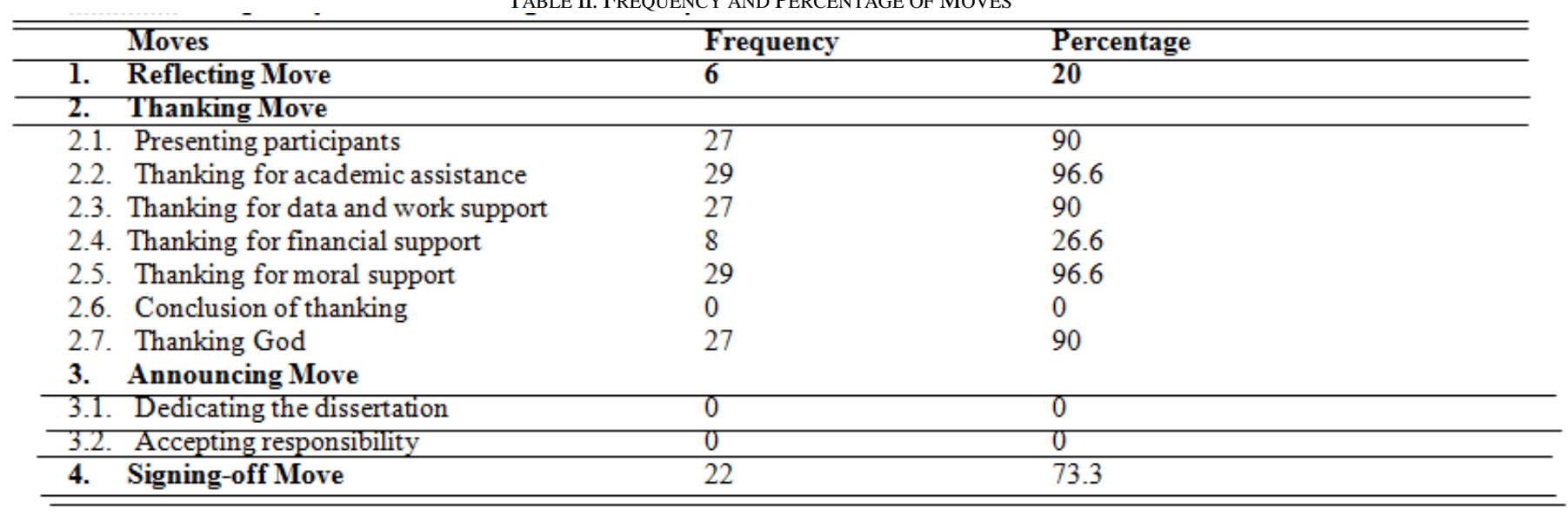

As indicated in Table 2, the highest frequency of 29 or $96.6 \%$ are thanking for academic assistance and thanking for moral support which are considered as an obligatory step while conclusion of thanking, dedicating the dissertation, and 
accepting responsibility posted as the lowest with no used or $0 \%$. The frequent steps employed under thanking moves are presenting participants, thanking for data and documentation, and thanking God with 27 or $90 \%$ respectively. Unlike Hyland (2004), no announcing move was found. The signing off move was evident and considered as an additional move. Only the second move, the thanking move, was obligatory. Thanking God was added as part of the thanking move.

\section{Reflecting Move}

Based on Hyland's (2004) research, this move presents the introspective comment of the writer's experiences while conducting the study. However, only 6 or $20 \%$ of the selected corpora employed this move. According to Hyland (2004), reflecting and announcing moves are optional. This can be inferred that announcing move might also optional to Filipino conventions of writing. The result is also in agreement with the study conducted by Mingwei and Yajun (2010) wherein reflecting move was one of the lowest frequencies.

\section{Thanking Move}

2.1 Presenting the Participants

Like in the previous researches of Hyland (2004), Al-Ali (2006), and Roungtheera (2010), this step represented the introduction of individuals and institutions, who will be thanked in the next step due to their contributions to the completion of the theses or dissertation.

Let us consider some examples.

(1) The researcher would like to extend her appreciation and gratitude to the following people who have supported her throughout this academic endeavour, to wit: (EM-004)

(2) The writer would like to express her grateful thanks, and real appreciation to the following individuals for their worthwhile contribution and assistance in making this research possible. (ENGL-001)

As clearly shown in the given examples, Filipino students seem to prefer to enumerate first all acknowledges followed by the discussion of any assistance in details. This indicates that they conform to the deductive style of writing moving from general to specific- a pattern they learned from their writing lessons in undergraduate programs.

\subsection{Thanking for Academic Assistance}

As clearly seen in Table 2, step 2.2 occurs 29 times or $96.6 \%$, and the person that is first to be thanked is the thesis adviser, followed by the panel/committee members and or experts in the particular field. Others are their research instructors, deans, other instructors, and their colleagues. Examples are illustrated below.

(3) Dr. X, the thesis adviser, for sharing his knowledge, expertise in reviewing this paper as well as enhancing the concept of the study. (ENGL-002)

(4) Mr. Y, my adviser, for his guidance, authentic comments, suggestion, generous contribution which gave this work clarity of purpose and content; for his patience checking researcher's works and understanding researcher's difficulties in dealing with the research. (GC-003)

(5) The member of the thesis committee, Dr. Z, Mr. M and
Dr. $\mathrm{N}$, for their comments and suggestions for the improvement of the thesis. (LIS-001)

As indicated in the examples above, the acknowledgers did not used academic ranks in acknowledging persons. This result is contrary to the study of Jaroenkitboworn (2014) where the Thai writers were particular in indicating academic ranks such as Professor, Asst. Professor, etc.

The titles such as Dr., Mr., Mrs., and Ms. preceding a proper name are used by the writers. This showed the Filipino conventions of writing business letters where students are taught to indicate titles to show formality and politeness.

Also, the results show that the writers usually mentioned first the complete names of acknowledgees followed by their administrative positions/job titles or designations.

2.3. Thanking for data and work support

This step contains thanks for data access, subjects' cooperation, editing help, and clerical and technical support. This type of thanking does not directly refer to academic work, but is related to the process of data collection and the production of the thesis or dissertation in terms of documentation. The people that provide data and permission for data collection or offer help, cooperation, or service for the sake of convenience and accuracy in producing the thesis to the author are thanked in this step.

Based on the data, this step occurred 27 times or $90 \%$. It appears that they are formally acknowledged at almost the same level as those in the step of thanking for academic assistance, even though their help is not the core of the acknowledgers' research. Let us consider some examples.

(6) Special gratitude to the school heads/principals of the six public elementary schools in $\mathrm{X}$ City for allowing the researcher to administer the survey questionnaire necessary in gathering data. (LIS-003)

(7) The author also extends her sincere gratitude to all her Grade-9 students of SY 2014-2015, who honestly answered the questionnaires and survey forms. (Math-003)

\subsection{Thanking for financial support}

As shown in Table 2, step 2.4 posted 8 occurrences or $26.6 \%$. It appears that only few of the total acknowledgers expressed their gratitude to those who financially supported them. Unlike other studies where different sources of funding or financial aid, including the state agencies were mentioned, the result show that the financial support of the writers mainly came from their parents and family members. Only one acknowledger expressed her gratitude for availing scholarship from her sending institution.

Some examples are given below.

(8) To Ms X, the researcher's sister, for her financial support extended to the researcher in order to finish this study. (Sci-004)

(9) My parents, $X$ and Y..... for the financial assistance, encouragements, words of wisdom, and for their upbringing. (GC-005)

(10) A heartfelt gratitude to Z University administration, for granting scholarship to the researcher. (LIS-003) 


\subsection{Thanking for moral support}

Like previous research, love, care, and encouragement are thanked for in this step. The participants or acknowledgees include mostly family members and friends. Let us consider some examples.

(11) Family, friends and colleagues, for their constant support, encouragement, patience, inspirations, and faithful prayers. (GC-002)

(12) To her parents, husbands, brothers, sister-in-law, relatives, friends, and colleagues, for their support and encouragement from the very start of this thesis till its completion. (Engl-003)

(13) Family and friends who are constantly there, providing moral support and inspiring words to keep her moving. (Math-005)

\subsection{Thanking God}

As mentioned earlier, this step is added because of its frequent occurrence in the study. It occurred 27 times or $90 \%$ which ranked next to thanking for academic assistance contrary to the study of Roungtheera (2010). This proved that Filipinos are truly religious who believed in God as Provider of every need. Thus, He is worthy of praise, thanks, and gratitude.

Most expressions of gratitude to God appeared both in the first and last paragraphs of the corpora. For expressions of thanks to God in the first paragraph, it reveals the Filipino belief that God should be the first place in all things. Filipinos, especially the Christians, believed that God as the creator and source of all things should be the first place in all things.

For expressions of thanks to the Almighty God in last and final paragraphs, it appears that Filipino writers followed the ascending degree of importance in developing a paragraph which starts from the least important to most important ideas. This is proven in the used of devices such as above all, most of all, and most importantly. Consider the following examples.

(14) The researcher would like to heartily express her gratitude and appreciation first and foremost to our Almighty, Jesus Christ who showered His blessings and wisdom that made the researcher able to work and face all the challenges while

TABLE III. LINGUISTIC FEATURES OF GRATITUDE EXPRESSION

\begin{tabular}{|c|c|c|}
\hline Forms & Examples & Occurrences \\
\hline Nominalization & $\begin{array}{l}\text { "Special thanks to...." } \\
\text { "My thanks go to..." }\end{array}$ & 9 \\
\hline Performative & $\begin{array}{l}\text { "We thank..." } \\
\text { "The researchers would like to thank..." }\end{array}$ & 33 \\
\hline Adjective & $\begin{array}{l}\text { "We are grateful to...." } \\
\text { "We are indebted to...." }\end{array}$ & 1 \\
\hline Passive Voice & $\begin{array}{l}\text { "X is thanked for..." } \\
\text { "Appreciation is given to..." }\end{array}$ & 3 \\
\hline Bare Mention & $\begin{array}{l}\text { "We have benefited from...." } \\
\text { "Y helped us.... }\end{array}$ & 0 \\
\hline & Total acts of gratitude & 46 \\
\hline
\end{tabular}

As shown in table 3 above, graduate students used more performative verbs than nouns, unlike what was revealed in working and preparing this research paper, and to the following who contributed much of their expertise, talents, and time to make the research endeavour possible. (GC-001)

(15) The researcher is above all grateful to the Almighty God, Merciful and Loving God for the Gift of life, good health, strength, knowledge, wisdom, enlightenment, guidance, inspiration and providing all the resources and all the blessing bestowed upon her. (LIS-003)

(16) Above all, to the Almighty God, the Great Provider, for all the grace, blessings, and strength. (EM-004)

(17) And most of all the Almighty God, the source of everything, for His divine mercy, love, protection and guidance, giving the researcher the courage, vitality and perseverance to hold on. (Math-004).

\section{Signing-off Move}

For the signing off move, which is an addition or modification of Hyland's (2004), it was in agreement to the results of study of Al-Ali (2010), where the students write their first and last name at the end of their acknowledgements.

As indicated in Table 2, signing off move occurred 22 times out of 30 or $73.3 \%$. It means that more than half of the writers employed the signing off move.

\section{B. Linguistic Features of Gratitude Expression}

Out of 30 acknowledgements, 46 acts of gratitude were found being used to realize steps in 2.1 to 2.7 of the thanking move. Following Hyland and Tse (2004), the gratitude expressions can be classified into 5 major ways as shown in table 3 . Most of the thanking steps contain overt expressions of gratitude realized with performative verbs garnering 33 occurrences whereas only few expressed through nominalization, adjective, and passive voice construction having 9,1 , and 3 occurrences respectively. No text expressed through bare mention, which is not an explicit thanking.
Hyland and Tse (2004), in which the uses of noun and verb patterns were almost the same in terms of quantity. 
TABLE IV. VERB PATTERNS OF GRATITUDE EXPRESSION

\begin{tabular}{lcc}
\hline \hline Forms & Examples & Occurrences \\
\hline Active & "The researcher thanks..." & 10 \\
& "The researcher expresses..." & 13 \\
Modal & "The researcher would like to express..." & 10 \\
Mental State & "The researcher wishes to... & $\mathbf{3 3}$ \\
\hline
\end{tabular}

Out of 33 performative acts, 13 or about $39 \%$ of their thanking verbs were prefaced by a modal would like to while 10 or about $30 \%$ were mental state verbs like wish to and want to. Ten out of 33 or about $30 \%$ of thanking acts were expressed in the active form of verbs. Consider the following examples.

(1) The researcher heartily expresses his sincerest thanks and appreciation to those who contributed their priceless support and cooperation in completion of this thesis. (EM-003)

(2) The researcher would like to acknowledge with deep gratitude the assistance of the following persons in the accomplishment of this work. (Engl-003)

(3) The writer wishes to express his deep appreciation and gratitude to all those who in one way or another helped make the undertaking a reality. (SCI-005)

\section{Modifiers in thanking acts}

Modifiers in thanking acts include adjectives (e.g. heartfelt, sincere, special, deep/est, most of all, and above all) and adverbs (e.g. humbly, sincerely, and heartily) which are often attached to thanking acts in their theses.

Most modifiers are found to be confined to steps 2.1 to 2.7 in this corpus. Most of them are appended to presenting the participants; for thanking God; and for moral support from parents, other family members, and friends. The results show that most these writers appended intense modifiers in the presentation parts of thanking. This is different from other studies wherein most modifiers are appended in step 2.2 or thanking for academic support.

\section{CONCLUSION}

To sum up, the generic structure of the acknowledgements written by SCC graduate students comprises two moves: the reflecting move and thanking move. Unlike Hyland (2004) and other related studies, no announcing move was found. Another move, the signing off move was evident and considered as an additional move. Only the second move, the thanking move, was obligatory. Thanking God was added as part of the thanking move.

Similar to previous studies, the acknowledgements in theses of SCC graduate students have certain structures and preferred linguistic features that conform to their socio-cultural context. The acknowledgements also reflect Filipino culture in terms of the way in which it shows religiosity which is proven in the frequent occurrences of thanking God and placing acts of gratitude to God in its highest importance. Another unique feature which was present in the corpora was the use of intense modifiers in thanking act in step 2.1 or presenting participants. Therefore, it can be said that, even though written in English, acknowledgements, as a genre, have to be in harmony with the sociocultural context where they are generated. This study can be viewed as another work that strengthens the definitions of genre as a socio-cultural practice (Bhatia, 2004) as well as the variety of Englishes that accompany a particular genre.

\section{ACKNOWLEDGEMENTS}

It is with utmost gratitude that I acknowledged Mr.Jerson Adlawon who helped me with the paper specifically in the analysis of each corpus.

\section{REFERENCES}

[1] N. Al-Ali, M.. "Conveying academic and social identity in graduate dissertation acknowledgments". in Claus-Peter Neumann, Ramón Plo Alastrué \& Carmen Pérez-Llantada Auría (Eds.), Proceedings of the fifth international AELFE conference. Zaragoza: Prensas Universitarias de Zaragoza. 35-42. 2006

[2] C. Bazerman. Shaping Written Knowledge: The Genre and Activity of the Experimental Article in Science. Madison, WI: University of Wisconsin Press. 1988

[3] V. Bhatia, K. Analysing Genre: Language Use in Professional Settings. London:Longman. 1993.

[4] D. Biber. Dimensions of Register Variation: A Cross-Linguistics Comparison. CUP. 199).

[5] D. Bunton. Generic moves in Ph.D. thesis Introductions. In J. Flowerdew (ed.), Academic Discourse. UK: Pearson Education. 57-75. 2002.

[6] R. Holmes. Genre analysis, and the social sciences: An investigation of the structure of research article discussion sections in three disciplines. English for Specific Purposes, 16, 321-337. 1997.

https://doi.org/10.1016/S0889-4906(96)00038-5

[7] K. Hyland. Disciplinary Discourses: Social Interactions in Academic Writing. London: Pearson. . 2000.

[8] K. Hyland. Graduates' gratitude: The generic structure of dissertation acknowledgements. English for Specific Purposes, 23, 303-324. 2004.

[9] K. Hyland \& P. Tse Acknowledgements in graduate dissertations. Applied Linguistics, 14, 259-275.2004.

[10] K. Jaroenkitboworn. A study of English acknowledgments written by EFL Thai students.PASAA. 47, pp. 98-127.2014.

[11] J. Nicolaisen.. Structure-based interpretation of scholarly book reviews: A new research technique. Proceedings of the Fourth International Conference on Conceptions of Library and Information Science, 123-135. 2002.

[12] K. Nwogu, N. Discourse Variation in Medical Texts. Monographs in Systemic Linguistics, Vol. 2. 1990. 
[13] S. Posteguillo. The schematic structure of Computer Science research articles. English for Specific Purposes.1999. https://doi.org/10.1016/S0889-4906(98)00001-5

[14] T Roungtheera. Acknowledgement in Theses Written in French by Thai Graduate Students: A Generic Structure and Socio-Cultural Aspects. Kasetsart Journal (Soc. Sci), 31: 153 - 165. (Published in Thai) 2010.

[15] J. Swales M. Aspects of Article Introductions. Language Studies Unit: Aston University. 198
[16] J. Swales. Genre Analysis: English in Academic Research Settings. Cambridge: Cambridge University Press. 1990.

[17] G.Thompson. Interaction in academic writing learning. Applied Linguistics, 22(1), 58-78. (2001). https://doi.org/10.1093/applin/22.1.58 